\title{
Ceramide Enhances Acrosomal Exocytosis Triggered by Calcium and the Calcium Ionophore A23187 in Boar Spermatozoa
}

\author{
Tetsuma MURASE ${ }^{1,3)}$, Noriaki IMAEDA ${ }^{4)}$, Naho KONDOH ${ }^{1)}$ and \\ Toshio TSUBOTA ${ }^{2,3}$
}

${ }^{1)}$ Laborartoty of Veterinary Theriogenology, ${ }^{2}$ Laboratory of Zoo and Wildlife Medicine, Division of Veterinary Medicine, Faculty of Applied Biological Sciences, ${ }^{3)}$ The United Graduate School of Veterinary Sciences, Gifu University, Yanagido 1-1, Gifu 501-1193, ${ }^{4)}$ Swine Research Department, Gifu Prefectural Livestock Research Institute, Maehira-cho 3-8, Minokamo, Gifu 505-0037, Japan

\begin{abstract}
Mammalian spermatozoa must undergo acrosomal exocytosis prior to penetration of the oocyte at fertilization. The mechanisms underlying acrosomal exocytosis have not yet been fully elucidated. This study explored the possible involvement of ceramide in exocytosis of the boar sperm acrosome. Ejaculated boar spermatozoa, stored with the Beltsville TS extender at 17C for up to 3 days, were washed and preincubated for $10 \mathrm{~min}$ with $\mathrm{C}_{2}$-ceramide, an analogue of endogenous ceramide, $\mathrm{C}_{2}$-dihydroceramide $\left(\mathrm{C}_{2}\right.$-DH-ceramide), a negative control to $\mathrm{C}_{2}$-ceramide, or with (1S,2R)-D-erythro-2(N-myristoylamino)-1-phenyl-1-propanol (D-erythro-MAPP), an inhibitor of alkaline ceramidase, followed by incubation and stimulation with $3 \mathrm{mM} \mathrm{Ca}{ }^{2+}$ and $0.3 \mu \mathrm{M}$ A23187 $\left(\mathrm{Ca}^{2+} / \mathrm{A} 23187\right)$ at $37 \mathrm{C}$ in air in a water bath. Spermatozoa fixed at specific intervals were examined, and the \% of acrosomal exocytosis was monitored. Stimulation of spermatozoa with $\mathrm{Ca}^{2+} / \mathrm{A} 23187$ resulted in a timedependent increase. There were no obvious changes at $5 \mathrm{~min}$, but this was followed by a rapid increase at $10 \mathrm{~min}$, reaching nearly a maximum level after $15 \mathrm{~min}$ or more of incubation. Preincubation with $\mathrm{C}_{2}$-ceramide or D-erythro-MAPP enhanced acrosomal exocytosis triggered by $\mathrm{Ca}^{2+} / \mathrm{A} 23187$ in a dose-dependent manner, whereas $\mathrm{C}_{2}$-DH-ceramide was without effect. These results suggest the possibility that ceramide may be involved in the mechanisms underlying acrosomal exocytosis.
\end{abstract}

Key words: Spermatozoa, Ceramide, Boar, A23187, Acrosomal exocytosis

(J. Reprod. Dev. 50: 667-674, 2004)

M ammalian spermatozoa undergo exocytosis of the acrosome, a single large granule, at fertilization in response to oocyte-derived stimuli, namely progesterone and zona pellucida glycoprotein [1, 2]. Acrosomal exocytosis can be induced in vitro by natural agonists but also by treatment with $\mathrm{Ca}^{2+}$ and the $\mathrm{Ca}^{2+}$ ionophore $\mathrm{A} 23187$

Accepted for publication: September 14, 2004

Correspondence: T. Murase (e-mail: muraset@cc.gifu-u.ac.jp)
$[3,4]$.

Molecular mechnisms underlying acrosomal exocytosis, which ends in membrane fusion of the outer acrosomal membrane and the plasma membrane, have been extensively investigated. Studies have revealed that after $\mathrm{Ca}^{2+}$ entry, a variety of pathways are sequentially activated leading to membrane fusion. Polyphosphoinositide breakdown takes place very early following $\mathrm{Ca}^{2+}$ entry, thereby generating 
diacylglycerol (DAG) [3,5]. Two pathways have been suggested in the generation of DAG: one via the activation of phosphoinositide-specific phospholipase C (PIC) [3], and the other via phosphatidylcholine-specific phospholipase C [6]. DAG then stimulates phospholipase $A_{2}[7,8]$, as such plays a second messenger role [9]. Fusigenic metabolites are generated by the action of $\mathrm{PLA}_{2}$ to bring about membrane fusion. A product of $\mathrm{PLA}_{2}$, lysophosphatidylcholine, mediates the final steps of membrane fusion in conjunction with rab3A protein, a small GTPase, via the cAMP/PKA pathway [10].

Another line of research has shown that a soluble NSF (N-ethyl-maleimide-sensitive fusion protein) attachment protein receptor (SNARE) may regulate membrane fusion [11]. V-SNARE is located on the vesicle membrane while t-SNARE is present on the plasma membrane [12]. Both combine to produce a complex for membrane fusion, and this mechanism has also been suggested as regulating membrane fusion in acrosomal exocytosis [13, 14].

Despite efforts to understand the molecular mechnisms underlying acrosomal exocytosis in mammalian spermatozoa, much remains to be clarified about the events leading to membrane fusion. The sphingomyelin cycle has been recognized as an important signalling pathway involved in many cell types and, upon activation, sphingomyelin is hydrolyzed into phosphorylcholine and ceramide, the latter playing an activator role $[15,16]$. A messenger role for ceramide in cells activated by tumour necrosis factor (TNF)- $\alpha[17,18]$, transforming growth factor$\beta$ [19], and $1 \alpha, 25$-dihydroxyvitamin $\mathrm{D}_{3}$ [19] has been demonstrated. In human spermatozoa, the involvement of a sphingomyelin/ceramide pathway has been suggested as playing a role in the capacitating processes [21], and a neutral sphingomyelinase has been identified in ram spermatozoa [22]. However, the role of ceramide in the mechanism underlying acrosomal exocytosis has not yet been investigated. Improving our knowledge of the molecular mechanisms underlying acrosomal exocytosis in mammalian spermatozoa, which is an essential step to fertilization, would help to clarify the factors reducing reproductive competence or to solve problems associated with it.

Using boar spermatozoa as a model, this study examined the possible involvement of ceramide in exocytosis of the sperm acrosome induced by $\mathrm{Ca}^{2+}$ and the $\mathrm{Ca}^{2+}$ ionophore A23187.

\section{Materials and Methods}

\section{Collection of spermatozoa}

The sperm-rich fraction of semen was collected by the gloved-hand method from a mature fertile Large White boar kept at the Swine Research Department of the Gifu Prefectural Livestock Research Institute, Gifu, Japan. Immediately after collection, sperm motility was assessed subjectively under a phase-contrast microscope. The \% of motile spermatozoa was also subjectively evaluated, and the gross appearance of sperm motion (motility grade) was classified into 5 categories: -(all immotile), \pm (motile without progression), + (progressively motile at low speed), ++ (progressively motile at moderate speed), +++ (progressively motile at the highest speed). Samples showing $>95 \%$ motile spermatozoa and with a category of motility grade +++ were used. Sperm concentration was also estimated by photometry (Celltac; model MEK-5254, Nihon Kohden, Tokyo, Japan). Semen was then diluted with the Beltsville TS extender [23] to give a concentration of $1.5 \times 10^{8} / \mathrm{ml}$ at room temperature. After dilution, the semen was protected from cold air, transported to the laboratory within $1.5 \mathrm{~h}$, then gradually cooled in a refridgerator, and stored at $17 \mathrm{C}$ for up to $72 \mathrm{~h}$ until use.

\section{Media}

Saline medium used for the washing and incubation of spermatozoa consisted of $142 \mathrm{mM}$ $\mathrm{NaCl}, 2.5 \mathrm{mM} \mathrm{KOH}, 10 \mathrm{mM}$ glucose, and $20 \mathrm{mM}$ Hepes, adjusted to $\mathrm{pH} 7.55$ at $20 \mathrm{C}$ with $\mathrm{NaOH}$ [3]. Saline medium consisting of $222 \mathrm{mM}$ sucrose in place of the $\mathrm{NaCl}$ was used for washing spermatozoa (sucrose medium; [3]). Both media contained $0.1 \mathrm{w} / \mathrm{v} \%$ polyvinyl alcohol (average molecular weight 9,000-10,000; Aldrich Chemical Co., MO, USA), and $0.1 \mathrm{w} / \mathrm{v} \%$ polyethylene glycol (Sigma Chemical Co., MO, USA). A stock solution of the calcium ionophore A23187 (Free acid; Calbiochem-Novabiochem Corp., CA, USA) was prepared at $30 \mu \mathrm{M}$ in dimethyl sulfoxide (DMSO) and diluted in saline medium to give a final concentration of $0.3 \mu \mathrm{M}$. N-acetyl-D-sphingosine ( $C_{2}$-ceramide; Sigma A7191), $C_{2}$-dihydro-ceramide 
( $\mathrm{C}_{2}$-DH-ceramide; Sigma C7980), and (1S,2R)-Derythro-2-(N-myristoylamino)-1-phenyl-1-propanol (D-erythro-MAPP; Biomol, SL-221) were dissolved in ethanol at $10 \mathrm{mM}$ and stored at $-30 \mathrm{C}$. After the solvent had been evaporated under a nitrogen gas stream at $40 \mathrm{C}$, they were dissolved in DMSO at 1 or $2.5 \mathrm{mM}$ for use. $\mathrm{C}_{2}$-ceramide, $\mathrm{C}_{2}$ - $\mathrm{DH}$-ceramide or D-erythro-MAPP in DMSO was added to the saline medium with $3 \mathrm{mM} \mathrm{CaCl} 2$ to give a final concentration of 10 or $25 \mu \mathrm{M}$ for sperm preincubation.

\section{Preparation and incubation of spermatozoa}

A portion of the stored semen $(2.5 \mathrm{ml})$ was placed in a test tube and left standing for about $5 \mathrm{~min}$ to allow the sedimentation of large cell clumps. The supernatant containing spermatozoa was overlayed onto a sucrose medium and centrifuged at $125 \mathrm{~g}$ for $5 \mathrm{~min}$, followed by $275 \mathrm{~g}$ for $7 \mathrm{~min}$ at room temperature. The supernatant was aspirated, and $200 \mu$ l of the loose pellets were mixed with $2 \mathrm{ml}$ of saline medium. Spermatozoa were then centrifuged at $275 \mathrm{~g}$ for $5 \mathrm{~min}$, and resuspended in saline medium with $3 \mathrm{mM} \mathrm{CaCl}$ for preincubation.

The suspended spermatozoa were pre-incubated at $37 \mathrm{C}$ in air in a water bath for $10 \mathrm{~min}$ in the presence or absence of $\mathrm{C}_{2}$-ceramide, $\mathrm{C}_{2}$-DHceramide or D-erythro-MAPP, and further incubated with $0.3 \mu \mathrm{M}$ A23187 for stimulation under the same conditions for $0,5,10,15$ and 30 min, except for the experiments using D-erythroMAPP, in which cells were incubated, for stimulation, for up to $15 \mathrm{~min}$.

Sperm concentration during preincubation and incubation was $2-5 \times 10^{7} / \mathrm{ml}$.

\section{Examination of acrosomal exocytosis, sperm motility and viability}

At various intervals, subsamples were taken and fixed by mixing with an equal volume of $2 \%$ glutaraldehyde/0.165 M cacodylate buffer $(0.165 \mathrm{M}$ sodium cacodylate, $\mathrm{pH}$ 7.3). Spermatozoa were examined under a light microscope $(400 \times)$, and acrosomal exocytosis was monitored as previously described [24]: spermatozoa showing a dense apical ridge of the head were considered as being acrosome-intact, and the others as having undergone acrosomal exocytosis.

Experiments were carried out 3 times each for $\mathrm{C}_{2}-$ ceramide, $\mathrm{C}_{2}$-DH-ceramide and D-erythro-MAPP.

In order to check a non-specific effect of the additives on spermatozoa, sperm samples incubated without A23187 were examined for the $\%$ of motile spermatozoa as described above and viable spermatozoa (\% viability) by the eosinnigrosin method immediately after the end of the incubation period. Sperm motility and viability were examined in each experiment except for Derythro-MAPP, where the number of replicates was 2.

\section{Statistical analyses}

Results are presented as average \pm standard error of the mean (SEM). Differences in the \% of acrosomal exocytosis and that of viability were tested by Student's $t$-test, F-test or 2-factor analysis of variance (ANOVA). After the F-test, data between the two groups were compared by Duncan's multiple range test. Differences with $\mathrm{P}<0.05$ were regarded as statistically significant.

\section{Results}

Stimulation of spermatozoa with $3 \mathrm{mM} \mathrm{Ca}^{2+}$ and $0.3 \mu \mathrm{M}$ A23187 $\left(\mathrm{Ca}^{2+} / \mathrm{A} 23187\right)$ resulted in a timedependent increase in the \% of acrosomal exocytosis. There were no obvious changes at 5 min, but this was followed by a rapid increase at 10 min, reaching nearly a maximum level at 15 min or more of incubation (Fig. 1). No major changes in this profile of response were noted after storage with BTS for different periods of time up to 3 days (data not shown). Preincubation of cells with $\mathrm{C}_{2-}$ ceramide enhanced the acrosomal exocytosis induced by $\mathrm{Ca}^{2+} / \mathrm{A} 23187$ in a dose-dependent manner (2-Factor ANOVA; time, $\mathrm{P}<0.001$, treatment, $\mathrm{P}<0.001$ among $\mathrm{Ca}^{2+} / \mathrm{A} 23187,+10 \mu \mathrm{M}$ $\mathrm{C}_{2}$-ceramide, and $+25 \mu \mathrm{M} \mathrm{C}_{2}$-ceramide; time $\times$ treatment, $\mathrm{P}=1$ ). The $\%$ of acrosomal exocytosis was increased slightly but significantly by incubation without A23187 although it did not vary significantly among the different concentrations of $\mathrm{C}_{2}$-ceramide (2-Factor ANOVA; time, $\mathrm{P}<0.006$; treatment, $\mathrm{P}>0.08$ among $\mathrm{Ca}^{2+}$ alone, $\mathrm{Ca}^{2+} / 10 \mu \mathrm{M}$ $\mathrm{C}_{2}$-ceramide, and $\mathrm{Ca}^{2+} / 25 \mu \mathrm{M} \mathrm{C}_{2}$-ceramide; time $\times$ treatment, $\mathrm{P}>0.84$; Fig. 1). Sperm motility after the end of incubation was $95.0 \pm 0.0 \%$ in each of $\mathrm{Ca}^{2+}$ alone, $\mathrm{Ca}^{2+} / 10 \mu \mathrm{M}$ ceramide, and $\mathrm{Ca}^{2+} / 25 \mu \mathrm{M}$ ceramide, and was not signifincatly different among those samples (One-way ANOVA; $\mathrm{P}=1$ ). Although sperm viability after the end of 


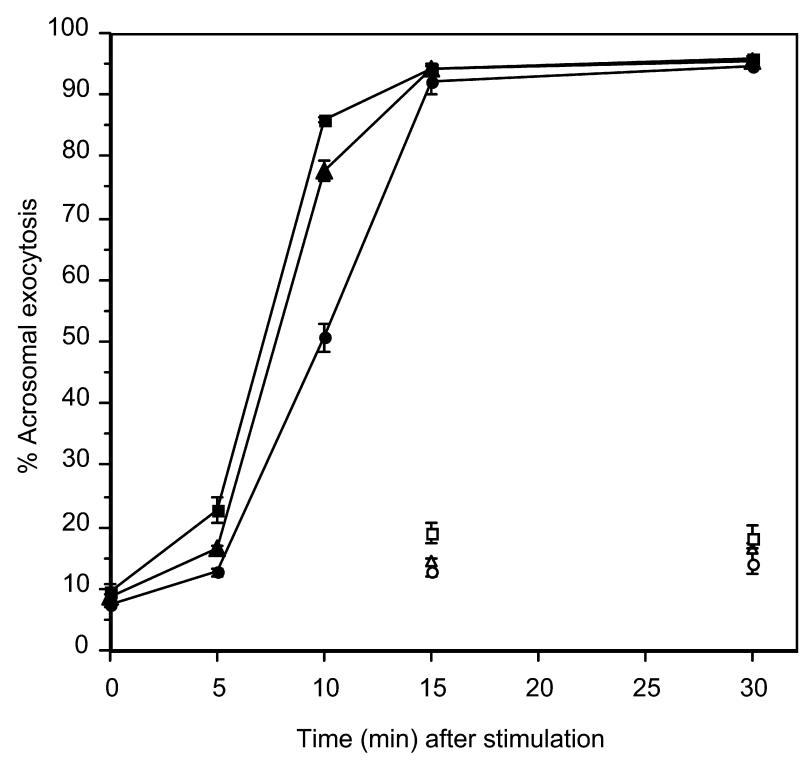

Fig. 1. Changes in \% of acrosomal exocytosis of boar spermatozoa stimulated with $\mathrm{Ca}^{2+}(3 \mathrm{mM})$ and $\mathrm{A} 23187$ $(0.3 \mu \mathrm{M})$ after preincubation in the presence or absence of $\mathrm{C}_{2}$-ceramide (10 or $25 \mu \mathrm{M}$ ) for $10 \mathrm{~min}$. Open circle, $\mathrm{Ca}^{2+}$ alone; open triangle, $\mathrm{Ca}^{2+} / 10 \mu \mathrm{M} \mathrm{C}_{2-}$ ceramide; open square, $\mathrm{Ca}^{2+} / 25 \mu \mathrm{M} \mathrm{C}_{2}$-ceramide; closed circle, $\mathrm{Ca}^{2+} / \mathrm{A} 23187$; closed triangle, $+10 \mu \mathrm{M}$ $\mathrm{C}_{2}$-ceramide; closed square, $+25 \mu \mathrm{M} \mathrm{C}_{2}$-ceramide.

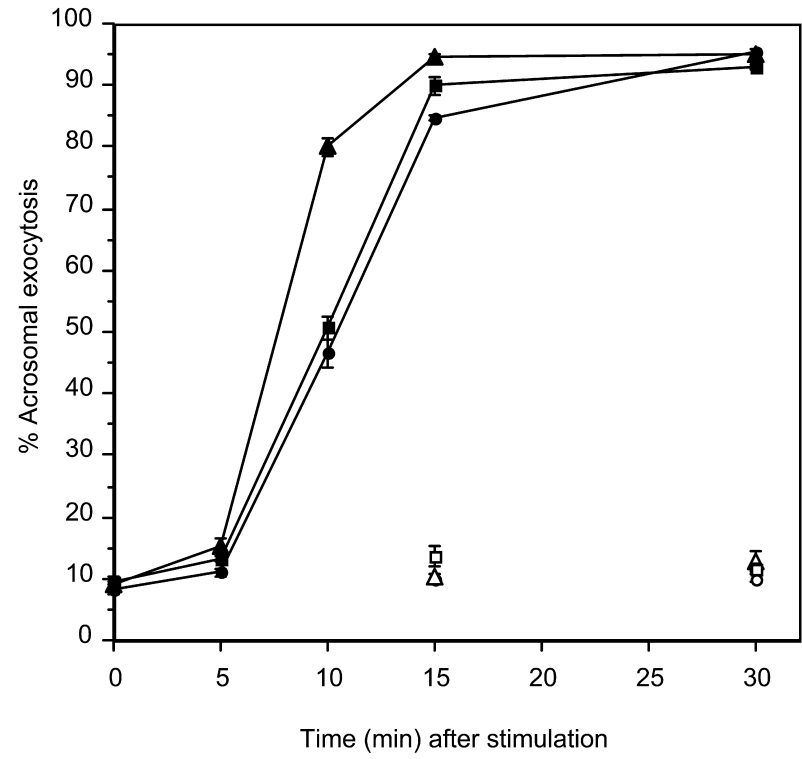

Fig 2. Changes in \% acrosomal exocytosis of boar spermatozoa stimulated with $\mathrm{Ca}^{2+}(3 \mathrm{mM})$ and $\mathrm{A} 23187$ $(0.3 \mu \mathrm{M})$ after preincubation in the presence or absence of $10 \mu \mathrm{M} \mathrm{C}_{2}$-ceramide or $\mathrm{C}_{2}$-DH-ceramide for 10 min. Open circle, $\mathrm{Ca}^{2+}$ alone; open triangle, $\mathrm{Ca}^{2+} /$ $10 \mu \mathrm{M} \mathrm{C}_{2}$-ceramide; open square, $\mathrm{Ca}^{2+} / 10 \mu \mathrm{M} \mathrm{C} \mathrm{C}_{2}$-DHceramide; closed circle, $\mathrm{Ca}^{2+} / \mathrm{A} 23187$; closed triangle, $+10 \mu \mathrm{M} \mathrm{C}_{2}$-ceramide; closed square, $+10 \mu \mathrm{M} \mathrm{C}_{2}$-DHceramide.

$\mathrm{P}>0.71$ ) or $10 \mu \mathrm{M} \mathrm{C}_{2}$-DH-ceramide (2-Factor ANOVA; time, $\mathrm{P}>0.19$; treatment, $\mathrm{P}>0.09$, between $\mathrm{Ca}^{2+}$ alone and $\mathrm{Ca}^{2+} / 10 \mu \mathrm{M} \mathrm{C}_{2}$-DH-ceramide; time $x$ treatment, $\mathrm{P}>0.70$ ) did not affect acrosomal exocytosis (Fig. 2). The \% of sperm motility (F-test; $\mathrm{P}=1$ ) and viability (F-test; $\mathrm{P}>0.31$ ) after the end of incubation without A23187 was not significantly different among $\mathrm{Ca}^{2+}$ alone (motility, $93.3 \pm 1.0$; viability, $87.3 \pm 2.0 \%), \mathrm{Ca}^{2+} / 10 \mu \mathrm{M} \mathrm{C}_{2}$-ceramide (motility, $93.3 \pm 1.0$; viability, $82.0 \pm 2.5 \%$ ), and $\mathrm{Ca}^{2+} / 10 \mu \mathrm{M} \mathrm{C}_{2}-\mathrm{DH}$-ceramide (motility, $93.3 \pm 1.0$; viability, $89.7 \pm 0.8 \%$ ).

In order to examine whether ceramide itself or its metabolites is involved in the possible pathways, Derythro-MAPP (an inhibitor of alkaline ceramidase which breaks down ceramide into sphingosine and fatty acid) was used to accumulate endogenous ceramide in spermatozoa after the beginning of stimulation. When spermatozoa were preincubated in the presence of D-erythro-MAPP, acrosomal exocytosis triggered by $\mathrm{Ca}^{2+} / \mathrm{A} 23187$ was enhanced in a dose-dependent manner (Fig. 3; F-test; time, $\mathrm{P}<0.0002$; treatment, $\mathrm{P}<0.0002$ among 


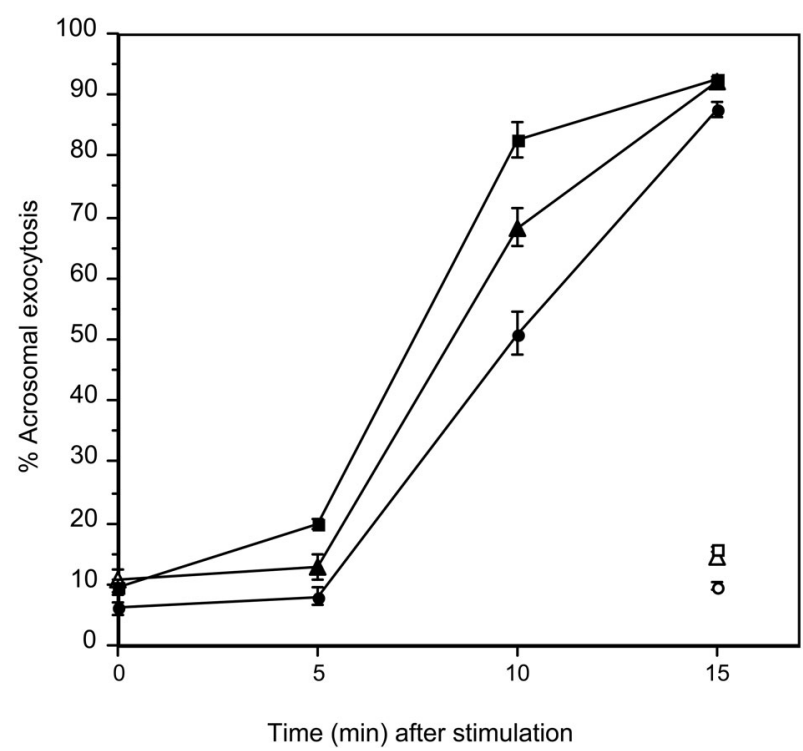

Fig. 3. Changes in \% of acrosomal exocytosis of boar spermatozoa stimulated with $\mathrm{Ca}^{2+}(3 \mathrm{mM})$ and $\mathrm{A} 23187$ $(0.3 \mu \mathrm{M})$ after preincubation in the presence or absence of D-erythro-MAPP (10 or $25 \mu \mathrm{M})$ for $10 \mathrm{~min}$. Open circle, $\mathrm{Ca}^{2+}$ alone; open triangle, $\mathrm{Ca}^{2+} / 10 \mu \mathrm{M}$ Derythro-MAPP; open square, $\mathrm{Ca}^{2+} / 25 \mu \mathrm{M}$ D-erythroMAPP; closed circle, $\mathrm{Ca}^{2+} / \mathrm{A} 23187$; closed triangle, $+10 \mu \mathrm{M}$ D-erythro-MAPP; closed square, $+25 \mu \mathrm{M}$ Derythro-MAPP.

$\mathrm{Ca}^{2+} / \mathrm{A} 23187$ and $+10 \mu \mathrm{M}$ and $+25 \mu \mathrm{M}$ D-erythroMAPP; time $\times$ treatment, $\mathrm{P}<0.008)$. Incubation with D-erythro-MAPP alone did not affect acrosomal exocytosis (2-Factor ANOVA; time, $\mathrm{P}>0.09$; treatment, $\mathrm{P}>0.32$; time $\times$ treatment $\mathrm{P}>0.47)$. Sperm motility (F-test; $\mathrm{P}>0.46$ ) or viability (F-test; $\mathrm{P}>0.32$ ) immediately after the end of incubation without A23187 did not differ among the samples preincubated with $\mathrm{Ca}^{2+}$ alone (motility, $90.0 \pm 0.0 \%$; viability, $83.0 \pm 1.4 \%), \mathrm{Ca}^{2+} / 10 \mu \mathrm{M}$ D-erythro-MAPP (motility, $90.0 \pm 0.0 \%$; viability, $83.0 \pm 1.4 \%$ ) or $\mathrm{Ca}^{2+} / 25 \mu \mathrm{M}$ D-erythro-MAPP (motility, $87.5 \pm 1.2 \%$; viability, $78.5 \pm 0.7 \%$ ).

\section{Discussion}

The response of spermatozoa to the ionophore A23187 was similar after different times of storage up to 3 days (data not shown), therefore it appears that capacitation did not occur during storage. Protein tyrosine phosphorylation is an important mechanism related to boar sperm capacitation [25,
26], but it was considered that chelating extracelluar calcium by the EDTA contained in BTS may have prevented tyrosine phosphorylation [27]. Recently, it has been reported that short-term storage with BTS keeps boar spermatozoa in a dormant state [28]. In this study the experiment was designed so that capacitation followed by acrosomal exocytosis was induced by the treatment with Ca and A23187 after storage.

The enhancement of acrosomal exocytosis by an exogenous ceramide analogue suggests that ceramide probably plays a role in acrosomal exocytosis. The specific action of exogenous ceramide on acrosomal exocytosis was supported by the observation that preincubation with $\mathrm{C}_{2-}$ ceramide alone did not affect the \% of acrosomal exocytosis during incubation without A23187. No significant changes in sperm motility by 10 or 25 $\mu \mathrm{M} \mathrm{C}_{2}$-ceramide alone were observed, while viability (measured based on the eosin incorporation) was reduced at the higher concentration $(25 \mu \mathrm{M})$ of $\mathrm{C}_{2}$-ceramide. The latter results were not in agreement with those of motility, which was not reduced at $25 \mu \mathrm{M}$. This discrepancy might have been due not to the influence on viability itself or to cytotoxicity as shown in HL-60 cells $(10 \mu \mathrm{M} \leq[15])$, but rather to possible changes in membrane fluidity or the permeability of spermatozoa by the effect of $25 \mu \mathrm{M}$ $\mathrm{C}_{2}$-ceramide [29]. The capacitating effect identified in human spermatozoa [21] might also explain this possible permeabilizing effect. The permeability of spermatozoa might have been increased at $25 \mu \mathrm{M}$ of $\mathrm{C}_{2}$-ceramide, resulting in changes in the dye incorporation of plasma membrane without altering sperm motility.

$\mathrm{C}_{2}$-ceramide has been extensively used as an analogue to endogenous ceramide to examine signalling pathways, and $\mathrm{C}_{2}-\mathrm{DH}$-ceramide serves as a negative control identical to $\mathrm{C}_{2}$-ceramide except in structures other than those lacking a trans $4-5$ double bond in a sphingoid base. The specific action of exogenous $\mathrm{C}_{2}$-ceramide was confirmed in this study by the lack of enhancement after preincubation in the presence of $\mathrm{C}_{2}$-DH-ceramide, a finding in agreement with the report by Bielawska et al. [30].

The origin of ceramide after stimulation and its target were not determined in this study. Cross [21] showed that sphingomyelin may be degenerated with the concomitant generation of 
ceramide during the capacitating processes of human spermatozoa, and suggested the role of ceramide in the capacitation of spermatozoa. Further studies will be required to determine ceramide formation and sphingomyelin degradation during sperm acrosomal exocytosis.

The observation that acrosomal exocytosis was enhanced by D-erythro-MAPP suggests that ceramide might be accumulated after stimulation and be further metabolized into sphingosine and free fatty acid by alkaline ceramidase in boar spermatozoa. Ceramides themselves, rather than their metabolites, might play a role in the sequence of events leading to membrane fusion, since, if the metabolites of ceramide were to have worked as signals, the reaction should have been inhibited by the action of D-erythro-MAPP [30]. Another explanation might be that the reduced generation of sphingosine by D-erythro-MAPP might have affected acrosomal exocytosis via a mechanism mediated by sphingosine, which has been recognized as a signaling molecule $[30,31]$. The enhancement of acrosomal exocytosis by exogenous $\mathrm{C}_{2}$-ceramide together with endogenous $\mathrm{C}_{2}$-ceramide accumulated by the action of Derythro-MAPP indicates that ceramide may be formed and may work as a signal during acrosomal exocytosis after stimulation with $\mathrm{Ca}^{2+}$ and A23187. Since no significant reduction in sperm motility and viability by $\mathrm{C}_{2}$-ceramide or D-erythro-MAPP were observed at the concentrations used $\left(C_{2}-\right.$ ceramide, $10 \mu \mathrm{M}$; D-erythro-MAPP,$\leq 25 \mu \mathrm{M})$, it was considered that the enhancement of acrosomal exocytosis was not due to degenerative changes by cell death.

De novo synthesis and the hydrolysis of sphingomyelin by sphingomyelinase are two possible pathways leading to ceramide generation. In TNF- $\alpha$ signaling, de novo synthesis via serine palmitoyltransferase action has been demonstrated [32].

Another route to generate ceramide after the stimulation of cells is the hydrolysis of sphingomyelin, which is considered to be a major pathway in the sphingomyelin cycle to generate ceramide [16]. Arachidonic acid generated by $\mathrm{PLA}_{2}$ action has been shown to be a mediator of sphingomyelin hydrolysis induced by TNF- $\alpha$ in human leukemia-derived HL-60 cells [33, 34]. It has also been demonstrated that, in L929 cells stimulated with TNF- $\alpha$, arachidonic acid generated by the action of cytosolic PLA $\mathrm{A}_{2}$ causes glutathione depletion followed by sphingomyelinase activation [18]. Although in boar spermatozoa, no decrease in the levels of sphingomyelin during capacitating processes was found [35], further studies will be required to examine the hydrolysis of sphingomyelin after stimulation for acrosomal exocytosis.

In ram spermatozoa stimulated with $\mathrm{Ca}^{2+}$ / A23187 for acrosomal exocytosis, diacylglycerol generated via PIC and PLC activation activates $\mathrm{PLA}_{2}$ to form lysophosphatidylcholine and arachidonic acid $[7,8]$, though the link between arachidonic acid generation and sphingomyelin breakdown in spermatozoa has yet to be established.

On the other hand, the effectors of ceramide have been investigated in somatic cells. Some of the suggested effectors include ceramide-activated protein kinases such as $\mathrm{p} 42 / \mathrm{p} 44$ mitogen-activated protein kinase and c-Jun $\mathrm{N}$-terminal-directed protein kinase [36] as well as ceramide-activated protein phosphatases $[16,37,38]$ and caspases [16]. Sphingomyelin degradation by sphingomyelinase action is followed by secretory $\mathrm{PLA}_{2}$ activation in MV1Lu cells [39], and PLA $A_{2}$ has also been suggested as a target of ceramide [37, 40]. The ceramide effectors mediating acrosomal exocytosis have not yet been investigated.

The present study suggests the possibility that ceramide may mediate acrosomal exocytosis in boar spermatozoa stimulated with $\mathrm{Ca}^{2+} / \mathrm{A} 23187$, and that ceramide itself, rather than its metabolites, may play a role in the sequence of events leading to membrane fusion. Further investigations are necessary to identify the formation of ceramides upon stimulation of spermatozoa.

\section{Acknowledgements}

The authors wish to thank Mr. Yamada of the Swine Research Department, Gifu Prefectural Livestock Research Institute, Gifu, Japan, for his assistance in the collection of boar semen. 


\section{References}

1. Yanagimachi R. Mammalian fertilization. In: Knobil E, Neill JD (eds.), The Physiology of Reproduction, 2nd ed. New York; Raven Press; 1994: 189-317.

2. Roldan ERS, Murase T, Shi Q-X. Exocytosis in spermatozoa in response to progesterone and zona pellucida. Science 1994; 266: 1578-1581.

3. Roldan ERS, Harrison RAP. Polyphosphoinositide breakdown and subsequent exocytosis in the $\mathrm{Ca}^{2+}$ / ionophore-induced acrosome reaction of mammalian spermatozoa. Biochem J 1989; 259: 397406.

4. Fraser LR, Abeydeera LR, Niwa K. $\mathrm{Ca}^{2+}$-regulating mechanisms that modulate bull sperm capacitation and acrosomal exocytosis as determined by chlortetracycline analysis. Mol Reprod Dev 1995; 40: 233-241.

5. Thomas P, Meizel S. Phosphatidylinositol 4,5bisphosphate hydrolysis in human sperm stimulated with follicular fluid or progesterone is dependent upon $\mathrm{Ca}^{2+}$ influx. Biochem J 1989; 264 : 539-546.

6. Roldan ERS, Murase T. Polyphosphoinositidederived diacylglycerol stimulates the hydrolysis of phosphatidylcholine by phospholipase C during exocytosis of the ram sperm acrosome. Effect is not mediated by protein kinase C. J Biol Chem 1994; 269: 23583-23589.

7. Roldan ERS, Fragio C. Phospholipase $\mathrm{A}_{2}$ activation and subsequent exocytosis in the $\mathrm{Ca}^{2+}$ /ionophoreinduced acrosome reaction of ram spermatozoa. $J$ Biol Chem 1993; 268: 13962-13970.

8. Roldan ERS, Fragio C. Diradylglycerols stimulate phospholipase $\mathrm{A}_{2}$ and subsequent exocytosis in ram spermatozoa. Biochem J 1994; 297, 225-232.

9. Roldan ERS, Harrison RAP. Diacylglycerol in the exocytosis of the mammalian sperm acrosome. Biochem Soc Trans 1993; 21: 284-289.

10. Garde J, Roldan ERS. rab3-Peptide stimulates exocytosis of the ram sperm acrosome via interaction with cyclic AMP and phospholipase $\mathrm{A}_{2}$ metabolites. FEBS Lett 1996; 391: 263-268.

11. Marash M, Gerst JE. t-SNARE dephosphorylation promotes SNARE assembly and exocytosis in yeast. EMBO J 2001; 20: 411-421.

12. Chen YA, Scheller RH. SNARE-mediated membrane fusion. Nat Rev Mol Cell Biol 2001; 2: 98106.

13. Tomes CN, Michaut M, De Blas G, Visconti P, Matti U, Mayorga LS. SNARE complex assembly is required for human sperm acrosome reaction. Dev Biol 2002; 243, 326-338.

14. Michaut M, Tomes CN, De Blas G, Yunes R, Mayorga LS. Calcium-triggered acrosomal exocytosis in human spermatozoa requires the coordinated activation of Rab3A and N- ethylmaleimide-sensitive factor. Proc Natl Acad Sci USA 2000; 97: 9996-10001.

15. Hannun YA, Obeid LM, Wolff RA. The novel second messenger ceramide: identification, mechanism of action, and cellular activity. Adv Lipid Res 1993; 25: 43-64.

16. Perry DK, Hannun YA. The role of ceramide in cell signaling. Biochim Biophys Acta 1998; 1436: 233-243.

17. Maguer-Satta V, Oostendorp R, Reid D, Eaves CJ. Evidence that ceramide mediates the ability of tumor necrosis factor to modulate primitive human hematopoietic cell fates. Blood 2000; 96: 4118-4123.

18. Hayter HL, Pettus BJ, Ito F, Obeid LM, Hannun YA. TNF $\alpha$-induced glutathione depletion lies downstream of cPLA 2 in L929 cells. FEBS Lett 2001; 507: 151-156.

19. Sato $\mathbf{M}$, Markiewicz $\mathbf{M}$, Yamanaka $\mathbf{M}$, Bielawska A, Mao C, Obeid LM, Hannun YA, Trojanowska M. Modulation of transforming growth factor- $\beta$ (TGF- $\beta$ ) signaling by endogenous sphingolipid mediators. J Biol Chem 2003; 278: 9276-9282.

20. Okazaki T, Bell RM, Hannun YA. Sphingomyelin turnover induced by vitamin $\mathrm{D}_{3}$ in HL-60 cells. Role in cell differentiation. J Biol Chem 1989; 264: 1907619080.

21. Cross NL. Sphingomyelin modulates capacitation of human sperm in vitro. Biol Reprod 2000; 63: 11291134.

22. Hinkovska VT, Petkova DH, Koumanov KS. A neutral sphingomyelinase in spermatozoal plasma membranes. Biochem Cell Biol 1987; 65: 525-528.

23. Johnson LA, Aalbers JG, Grooten HJG. Artificial insemination of swine: fecundity of boar semen stored in Beltsville TS (BTS), modified Modena (MM), or MR-A and inseminated on one, three and four days after collection. Zuchthyg 1988; 23: 49-55.

24. Shams-Borhan G, Harrison RAP. Production, characterization, and use of ionophore-induced, calcium-dependent acrosome reaction in ram spermatozoa. Gamete Res 1981; 4: 407-432.

25. Harayama H. Viability and protein phosphorylation patterns of boar spermatozoa agglutinated by the treatment with a cell-permeable cyclic adenosine 3',5'-monophosphate analog. J Androl 2003; 24: 831842.

26. Harayama H, Sasaki K, Miyake M. A unique mechanism for cyclic adenosine $3^{\prime}, 5^{\prime}$ monophosphate-induced increase of $32-\mathrm{kDa}$ tyrosine-phosphorylated protein in boar spermatozoa. Mol Reprod Dev 2004; 69: 194-204.

27. Dubé C, Tardif S, LeClerc P, Bailey JL. The importance of calcium in the appearance of p32, a boar sperm tyrosine phosphorylation, during in vitro capacitation. J Androl 2003; 24: 723-733.

28. Dubé C, Beaulieu M, Reyes-Moreno C, 
Guillemette C, Bailey JL. Boar sperm storage capacity of BYS and Androhep Plus: viability, motility, capacitation and tyrosine phosphorylation. Theriogenology 2004; 62: 874-886.

29. Simon CG Jr, Gear AR. Membrane-destabilizing properties of $\mathrm{C}_{2}$-ceramide may be responsible for its ability to inhibit platelet aggregation. Biochemistry 1998; 37: 2059-2069.

30. Bielawska A, Greenberg MS, Perry D, Jayadev S, Shayman JA, McKay C, Hannun YA. (1S,2R)-Derythro-2-(N-Myristoylamino)-1-phenyl-1-propanol as an inhibitor of ceramidase. J Biol Chem 1996; 271: 12646-12654.

31. Chao R, Khan W, Hannun YA. Retinoblastoma protein dephosphorylation induced by D-erythrosphingosine. J Biol Chem 1992; 267; 23459-23462.

32. Meyer SG, de Groot H. Cycloserine and threodihydrosphingosine inhibit TNF- $\alpha$-induced cytotoxicity: evidence for the imporatance of de novo ceramide synthesis in TNF- $\alpha$ signaling. Biochim Biophys Acta 2003; 1643: 1-4.

33. Jayadev S, Linardic CM, Hannun YA. Identification of arachidonic acid as a mediator of sphingomyelin hydrolysis in response to tumor necrosis factor $\alpha$.J Biol Chem 1994; 269, 5757-5763.

34. Jayadev S, Hayter HL, Andrieu N, Gamard CJ, Liu B, Balu R, Hayakawa M, Ito F, Hannun YA. Phospholipase $A_{2}$ is necessary for tumor necrosis factor $\alpha$-induced ceramide generation in L929 cells. I Biol Chem 1997; 272, 17196-17203.

35. Evans RW, Weaver DE, Clegg ED. Diacyl, alkenyl, and alkyl ether phospholipids in ejaculated, in utero-, and in vitro-incubated porcine spermatozoa. J Lipid Res 1980; 21: 223-228.

36. Conway A-M, Pyne NJ, Pyne S. Ceramidedependent regulation of $\mathrm{p} 42 / \mathrm{p} 44$ mitogen-activated protein kinase and c-Jun N-terminal-directed protein kinase in cultured airway smooth muscle cells. Cell Signal 2000; 12: 737-743.

37. Hannun YA. The sphingomyelin cycle and the second messenger function of ceramide. J Biol Chem 1994; 269: 3125-3128.

38. Kitatani K, Akiba S, Hayama M, Sato T. Ceramide accelerates dephosphorylation of extracellular signal-regulated kinase $1 / 2$ to decrease prostaglandin $\mathrm{D}_{2}$ production in RBL-2H3 cells. Arch Biochem Biophys 2001; 395: 208-214.

39. Zhao S, Du X-Y, Chai M-Q, Chen J-S, Zhou Y-C, Song J-G. Secretory phospholipase $\mathrm{A}_{2}$ induces apoptosis via a mechanism involving ceramide generation. Biochim Biophys Acta 2002; 1581: 75-88.

40. Koumanov KS, Momchilova AB, Quinn PJ, Wolf C. Ceramides increase the activity of the secretory phospholipase $\mathrm{A}_{2}$ and alter its fatty acid specificity. Biochem J 2002; 363: 45-51. 